\title{
Hepatitis B Virus Core Protein Variations Differ in Tumor and Adjacent Nontumor Tissues from Patients with Hepatocellular Carcinoma
}

\author{
Yu Zhu ${ }^{a, b}$ Yan Jinc Xiaojin Cai ${ }^{b}$ Xin Bai ${ }^{b}$ Min Chen ${ }^{c}$ Taoyang Chen ${ }^{d}$ \\ Jinbing Wang ${ }^{d}$ Gengsun Qianc $^{c}$ Jianren Gu ${ }^{b}$ Jinjun Li ${ }^{\text {b }}$ Hong Tu ${ }^{b}$

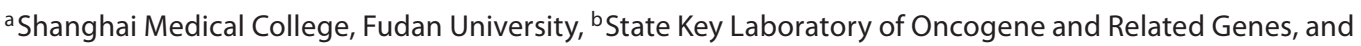 \\ 'Department of Molecular Diagnostics, Shanghai Cancer Institute, Renji Hospital, Shanghai Jiao Tong University \\ School of Medicine, Shanghai, and d Qidong Liver Cancer Institute/Qidong Tumor Hospital, Qidong, China
}

\section{Key Words}

Core protein · Hepatitis B virus $\cdot$ Hepatocellular carcinoma • Mutation-clustering region

\begin{abstract}
Objectives: To characterize the mutation pattern of a hepatitis $B$ virus (HBV) core protein ( $\mathrm{HBCAg}$ ) derived from hepatocellular carcinoma (HCC) and adjacent nontumor tissues. Methods: HBV core gene fragments (nt. 1901-2365) were amplified from 98 HBV-related HCC tissues and 33 adjacent nontumor tissues. The deduced amino acids (AAs) of the core gene were aligned with the prototype sequences of HBV genotypes B and C. Results: In total, there were 54 positions that showed polymorphism at the deduced AA level. The mutations were predominantly located in three major (codons 83-87, 95-104 and 130-135) and three minor (codons 21-38, 59-63 and 151-155) mutation-clustering regions (MCRs). The substitution rate in MCRs was significantly higher than in mutation-devoid regions $(p<0.001)$. The most frequently occurring mutations in rank were codon P130T (38.8\%), I97L (37.8\%) and S87G (23.5\%). In addition, there were 7 patients that showed internal deletions in the middle of $\mathrm{HBCAg}$ with sizes ranging from 34 to $59 \mathrm{AAs}$. Unexpectedly, the core genes isolated from tumor tissues had fewer mutations compared with those isolated from adjacent non-
\end{abstract}

tumor tissues from the same patients $(p<0.05)$. Conclusions: Accumulation of naturally occurring mutations in certain restricted segments of $\mathrm{HBCAg}$ may be related to the development of HCC.

Copyright $\odot 2011$ S. Karger AG, Basel

\section{Introduction}

Worldwide, more than 350 million people are chronically infected with the hepatitis B virus (HBV) and are at increased risk of developing hepatocellular carcinoma (HCC) [1]. In addition to host factors, viral factors per se can also play an important role in determining clinical outcomes [2,3].

$\mathrm{HBV}$ is a small, enveloped DNA virus of the Hepadnaviridae family. The virus has a partially double-stranded DNA genome of about $3.2 \mathrm{~kb}$ with four overlapping open reading frames that encode the viral envelope protein (pre-S/S), the X protein (X), the DNA polymerase $(\mathrm{P})$ and the core protein (precore/core). HBV replicates via a reverse transcription reaction with an RNA intermediate. As the reverse transcriptase lacks proofreading activity, errors in $\mathrm{HBV}$ replication occur at a much higher rate than in other DNA viruses. Hence, various mutations can be observed in the HBV genome during long-term infec-

\section{KARGER}

Fax +41613061234

E-Mail karger@karger.ch

www.karger.com (c) 2011 S. Karger AG, Basel

0300-5526/12/0551-0029\$38.00/0

Accessible online at:

www.karger.com/int
Hong Tu, MD, PhD

Shanghai Cancer Institute, Renji Hospital

Shanghai Jiao Tong University School of Medicine

2200-25 Xietu Road, Shanghai 200032 (China)

Tel. +86216443 7301, Fax +86216443 7196, E-Mail tuhong@shsci.org 
tion; some of these markers can serve as viral markers for predicting the development of HBV-associated HCC. The HBV genotype, basal core promoter mutation, precore mutation and pre-S deletion have been implicated in the development of HCC [4-8]. However, the association of core gene mutation and HCC has been largely unexplored. While several mutation hot-spots, such as codons $5,13,59,60,87,97$ and 130 of the hepatitis B core antigen ( $\mathrm{HBcAg}$ ), have been identified in HBV chronic carriers [9-13], only a few have been reported to increase the risk of HCC [14]. Recently, six mutations at HBcAg codons 13, $21,49,79,113$ and 181 were reported to decrease the risk of HCC. The protective effects of these variants on HCC may be attributable to the reduced level of viral load and HBV e antigen negativity [15].

Qidong, an east coastal city in Jiangsu province, China, is a hyperendemic area of $\mathrm{HBV}$. The province also leads in the incidence of HCC in China $[16,17]$. To assess the potential role of HBV core gene mutations in developing HCC, we examined the HBV sequences from nt. 1901 to 2365 in 98 HCC tissues collected in Qidong City. Thirty-three paired tumor and adjacent nontumor tissues were employed, for the first time, to compare the mutation rate and pattern of $\mathrm{HBcAg}$ in these tissues.

\section{Materials and Methods}

\section{Patients and Tissue Samples}

Ninety-eight HCC tumor tissues and 33 corresponding nontumor liver tissues were obtained from patients with HCC who underwent surgical resection at the Qidong Liver Cancer Institute/Qidong Tumor Hospital from 1996 to 2006. All participants were histologically diagnosed with HCC and were seropositive for hepatitis B surface antigen and HBV DNA (mean \pm SD, $3.68 \pm$ $0.81 \log$ copies $/ \mathrm{ml}$ ). HCC patients were at stage A1 (BCLC staging system). Tumor grade was II, II-III and III in 47, 9 and 42 cases, respectively. Patients with hepatitis $C$ virus coinfection were excluded from the study. Ninety patients were men and 8 were women. Patients' ages ranged from 32 to 75 years (mean, 49 years). The average duration of hepatitis B before the diagnosis of HCC was 14.5 years. None of the patients had received treatment with interferon or nucleotide analogues. Thirty patients had been treated with Chinese herbal preparations to alleviate the inflammation and improve liver function. There were 55 patients who had been diagnosed with liver cirrhosis before HCC occurrence. Fresh tumor and nontumor liver tissues were snap-frozen in liquid nitrogen and stored at $-70^{\circ}$ until use. This work was performed in accordance with the Helsinki Declaration. Written informed consent was obtained from all patients and the study protocol was approved by the institutional review boards of the Qidong Liver Cancer Institute/Qidong Tumor Hospital and the Shanghai Cancer Institute, Renji Hospital, Shanghai Jiao Tong University School of Medicine.

\section{DNA Extraction from Tissue}

One hundred milligrams from each sample of frozen liver tissue was cut into small fragments and incubated with $600 \mu l$ lysis buffer (10 mM Tris-HCl, pH 8.0, 10 mM EDTA, 2.5\% SDS, $200 \mu \mathrm{g} /$ $\mathrm{ml}$ proteinase $\mathrm{K}$ ) at $50^{\circ}$ for $20 \mathrm{~h}$. After the tissues were homogenized, genome DNA was extracted by the conventional phenolchloroform method.

\section{Amplification and Sequencing of HBV Core Gene}

The HBV core gene from nt. 1901 to 2365 was amplified by semi-nested PCR using the sense primer pre-C F1, 5'TTCACCTCTGCCTAATCATCTC-3' (nt. 1824-1845) and the antisense primer HBV2570R, 5'-AATGTCCTCCTGTAAATGAATG-3' (nt. 2570-2549) as the first round primers, and the sense primer pre-C F1 and the antisense primer HBV2433R, 5'GATTGAGATCTTCTGCGACGC-3' (nt. 2433-2413) as the second round primers. PCR was performed under the following conditions: $94^{\circ}$ for $3 \mathrm{~min}$, followed by $94^{\circ}$ for $30 \mathrm{~s}, 58^{\circ}$ for $30 \mathrm{~s}$ and $72^{\circ}$ for $1 \mathrm{~min}$ for 35 cycles with a final extension at $72^{\circ}$ for $7 \mathrm{~min}$. The PCR products were gel purified (Axygen Scientific, Inc., Union City, Calif., USA) and used as templates for sequencing using the BigDye terminator cycle-sequencing reaction kit and the Prism 3700 DNA analyzer (Applied Biosystems, Foster City, Calif., USA). Sequences of the core gene were compared using MEGA4.1 [18].

\section{HBV Genotyping}

HBV genotypes were determined by comparing the sequence of the $\mathrm{X}$ gene with a set of database-derived standard sequences. Standard sequences were retrieved from GenBank/DDBJ/ EMBL. The phylogenetic tree was constructed with the software MEGA4.1 [18].

\section{Statistical Analysis}

Student's t test was used for continuous variables with normal distributions. All of the tests were two-tailed, and a $\mathrm{p}$ value of $<0.05$ was considered statistically significant. SPSS (SPSS Inc. Chicago, Ill., USA) version 12.0 was used for the statistical analysis.

\section{Results}

\section{Nucleotide Sequence and Deduced Amino Acid Residue of the HBV Core Gene Isolated from 98 HCC Tissues}

HBV DNA fragments (nt. 1901-2365) were successfully amplified by PCR from 98 HCC tissues. This region was translated into the first 155 amino acids (AAs) of the core protein. Among the $98 \mathrm{HBV}$ isolates, 90 belonged to genotype $\mathrm{C}$ and 8 belonged to genotype $\mathrm{B}$. Available nucleotide sequences GU434373 and GU434374 from GenBank were used as the prototype sequences for genotype $\mathrm{B}$ and $\mathrm{C}$, respectively. These two viral strains were isolated from HBV carriers in the Qidong area. In total, 54 sites with missense mutations were found when aligned 


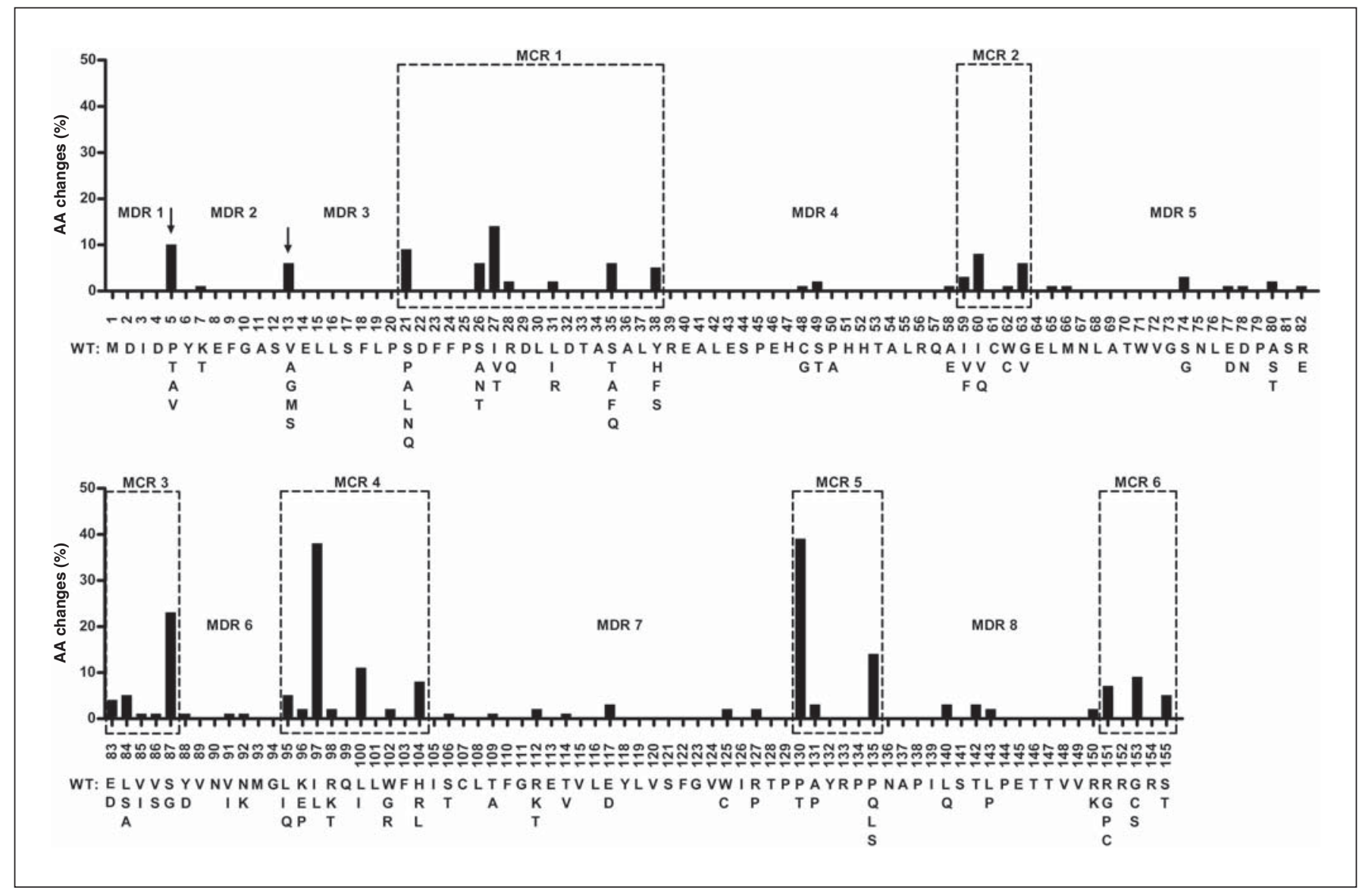

Fig. 1. Distribution of AA changes in the HBV core protein. The first 155 AAs of the core protein were aligned with prototype sequences of HBV. Six MCRs and eight MDRs were identified. WT = Wild type.

to the respective prototype sequence (fig. 1). Seventy-nine patients $(80.6 \%)$ showed at least one missense mutation within the detected core region. The mutations most frequently occurred at codon 130 (38.8\%), codon 97 (37.8\%) and codon 87 (23.5\%). The substitution rate at each AA residue was $0.0123 \pm 0.0333$.

\section{Mutation-Clustering Regions and Hot-Spot Sites of $H B V$ Core Protein}

The distribution pattern of $54 \mathrm{AA}$ alterations is presented in figure 1 . Most of the changes clustered in small segments. The six mutation-clustering regions (MCRs) were codons 21-38 (MCR1), codons 59-63 (MCR2), codons 83-87 (MCR3), codons 95-104 (MCR4), codons 130-135 (MCR5) and codons 151-155 (MCR6). We tentatively defined MCR3, MCR4 and MCR5 as the major domains and MCR1, MCR2 and MCR6 as the minor domains. The mutation rates ranged from 0.0561 to 0.0694 in the major domains and from 0.0249 to 0.0421 in the minor domains. In addition to the MCRs, two point mutations located at codon 5 and codon 13 were found to occur with high frequency. Between the MCRs and hotspot point mutations, eight mutation-devoid regions (MDRs) were tentatively defined. The average mutation rate in the MDRs was $0.0032 \pm 0.0078$, which was significantly lower than that in the major domains $(\mathrm{p}<$ $0.001)$ or minor domains $(\mathrm{p}<0.001)$. These data indicate that the distribution of mutations in HBV core protein is not random.

\section{Internal Deletion of HBV Core Protein}

Among the $98 \mathrm{HBV}$ sequences isolated from HCC tissues, $7(7.1 \%)$ had internal deletions in the core gene. The deletions ranged in size from 102 to $177 \mathrm{bp}$, which caused 34-59 AA truncations in the middle of the core protein (fig. 2). No deletion caused frameshift alterations as the 
Fig. 2. HBV core protein deletion mutants in tumor tissues. The first 155 AAs of core protein are shown as bars. Parts in black indicate deletion regions.

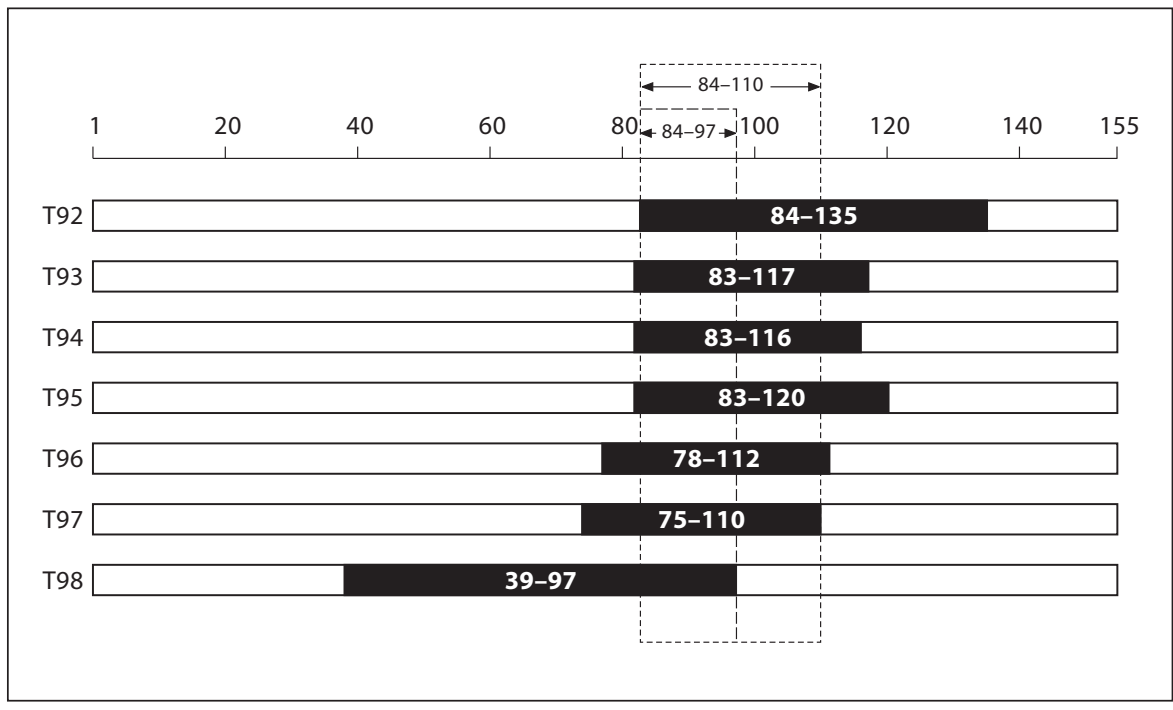

Table 1. Comparison of AA changes in various regions of the HBV core protein isolated from tumor and nontumor tissues

\begin{tabular}{lclll}
\hline Region & Range & $\begin{array}{l}\text { Tumor tissue } \\
(\mathrm{n}=33)\end{array}$ & $\begin{array}{l}\text { Nontumor tissue } \\
(\mathrm{n}=33)\end{array}$ & $\begin{array}{l}\mathrm{p} \\
\text { value }\end{array}$ \\
\hline MCRs & & & & \\
MCR1 & $21-38$ & $0.0185 \pm 0.0300$ & $0.0202 \pm 0.0335$ & 0.830 \\
MCR2 & $59-63$ & $0.0121 \pm 0.0485$ & $0.0485 \pm 0.1004$ & 0.065 \\
MCR3 & $83-87$ & $0.0606 \pm 0.0933$ & $0.0970 \pm 0.1132$ & 0.159 \\
MCR4 & $95-104$ & $0.0758 \pm 0.0867$ & $0.0848 \pm 0.0795$ & 0.659 \\
MCR5 & $130-135$ & $0.0606 \pm 0.0814$ & $0.0606 \pm 0.1005$ & 1.000 \\
MCR6 & $151-155$ & $0.0242 \pm 0.0830$ & $0.0121 \pm 0.0485$ & 0.472 \\
\hline MDRs & & & & \\
MDR1 & $1-4$ & $0.0000 \pm 0.0000$ & $0.0000 \pm 0.0000$ & 1.000 \\
MDR2 & $6-12$ & $0.0076 \pm 0.0303$ & $0.0114 \pm 0.0365$ & 0.648 \\
MDR3 & $14-20$ & $0.0000 \pm 0.0000$ & $0.0043 \pm 0.0249$ & 0.321 \\
MDR4 & $39-58$ & $0.0000 \pm 0.0000$ & $0.0091 \pm 0.0232$ & 0.028 \\
MDR5 & $64-82$ & $0.0000 \pm 0.0000$ & $0.0207 \pm 0.0415$ & 0.006 \\
MDR6 & $88-94$ & $0.0043 \pm 0.0249$ & $0.0043 \pm 0.0249$ & 1.000 \\
MDR7 & $105-129$ & $0.0024 \pm 0.0097$ & $0.0073 \pm 0.0186$ & 0.189 \\
MDR8 & $136-150$ & $0.0061 \pm 0.0256$ & $0.0020 \pm 0.0116$ & 0.412 \\
\hline Total & $1-155$ & $0.0141 \pm 0.0112$ & $0.0217 \pm 0.0163$ & 0.030 \\
\hline & & & &
\end{tabular}

sizes of the nucleotide deletion were in multiples of three. In all 7 cases, the deletions terminated upstream of the AUG translation initiation codon of the P gene (nt. 23072309 , corresponding to the core gene codon 136), thus leaving the HBV polymerase intact. The common region affected by the truncations was from codon 84 to 97 . If HCC case T98 were not considered, the common trun- cated region would extend up to codon 110 . This region (codons 84-110) involved two major mutation clustering domains, namely MCR3 and MCR4.

\section{Comparison of Core Mutations between 33 Paired}

Tumor and Nontumor Tissues

Thirty-three HCC tissues and the corresponding adjacent nontumor liver tissues were included in the study to compare the mutation rate and pattern of the HBV core gene. No internal deletion existed in these 33 paired tumor and nontumor tissues. The mutation rate of $\mathrm{HBcAg}$ in nontumor tissues was significantly higher than that in tumor tissues $(0.0217 \pm 0.0163$ vs. $0.0141 \pm 0.0112$, $\mathrm{p}<$ $0.05)$. Further analysis revealed that the elevated rate of mutation in nontumor tissues was mainly attributed to the AA changes in a small region between codon 39 and 82. This region is composed of one MCR (MCR 2) and two MDRs (MDR4/MDR5). While core sequences from 33 tumor tissues showed no missense mutation in MDR4 and MDR5, those from 33 nontumor tissues displayed the missense mutations at a rate of $0.0091 \pm 0.0232$ for MDR4 (p < 0.05) and $0.0207 \pm 0.0415$ for MDR5 (p < 0.01 ; table 1). In MCR2, which was located between MDR4 and MDR5, the mutation rate in nontumor tissues was also higher with boundary significance than in tumor tissues $(0.0485 \pm 0.1004$ vs. $0.0121 \pm 0.0485, \mathrm{p}=0.065)$. Throughout the core protein, only MCR6 and MDR8 showed slightly higher mutation numbers in the tumor group than in the nontumor group. 


\section{Discussion}

The HBV core gene encodes a single polypeptide of 183 AAs $(21 \mathrm{kDa})$ that assembles to form nucleocapsid particles. The core protein consists of two distinct domains: the N-terminal assembly domain (AA 1-149) that forms the contiguous spherical shell and the C-terminal protamine domain (AA 150-183) that is responsible for RNA packaging $[19,20]$. As the C-terminal protamine domain is quite conserved as reported by the previous studies [10, 21, 22], we analyzed only the nucleotide substitutions from nt. 1901 to 2365 in the present investigation. This DNA fragment encodes the N-terminal 155 AAs of $\mathrm{HBcAg}$, which contains the major known epitopes for CD4+ $\mathrm{T}$ cell, cytotoxic T lymphocyte (CTL) and $\mathrm{B}$ cell recognition [23-25]. While a large number of mutations in this region were observed in our study, they were mainly confined to three major and three minor MCRs. The average mutation rate in the MCRs was 0.0433 \pm 0.0381 , which was significantly higher than that in the other 'MDRs' $(p<0.001)$. These data indicate that the distribution of mutation in $\mathrm{HBcAg}$ is not random.

Most of the previous studies on core gene mutations were based on serum samples of chronic hepatitis patients [9-12, 21-23, 26, 27]; examples of molecular changes of $\mathrm{HBcAg}$ derived from the tumor tissues of HCC patients remain largely unexplored. To our knowledge, only Hosono et al. [28] has examined $\mathrm{HBcAg}$ sequences in 15 HCC tissues. They found that $\mathrm{HBcAg}$ mutations were predominantly within three major domains, i.e. codons $1-21$, codons $80-121$ and codons $130-135$. Our results are compatible with that study. We noticed two hot-spot mutations (P5T/A/V and V13A/G/M/S) in codons 1-21 and two major MCRs (MCR3 and MCR4) in codons 80-121. The third major MCR, MCR5 in our study, resided precisely in codons 130-135. These data suggest that the mutation pattern of $\mathrm{HBcAg}$ isolated from HCC tissues may share some common features. Compared with the $\mathrm{HBcAg}$ sequences derived from the sera of non-HCC patients $[9-12,21-23,26,27,29]$, those from HCC tissues displayed more AA changes at the $\mathrm{N}$-terminus of $\mathrm{HBcAg}$. Ohto's group reported that in patients with severe liver damage (including chronic active hepatitis, cirrhosis, fulminant hepatitis and acute exacerbation to liver failure), $\mathrm{HBcAg}$ mutations were frequently found in codons 48-60 and codons $84-101$ [10, 21, 22]. Hur et al. [12] later confirmed in a longitudinal observation that during the progression of chronic active hepatitis, the mutations gradually accumulated in a small segment of codons 84-97. Akarca and Lok [9] reported that the mu- tations associated with active liver disease were clustered in the middle of $\mathrm{HBcAg}$, i.e. codons 59-66, codons 87100, codons 125-135 and codons 147-155. Carman et al. [26] reported that the HBcAg mutations were concentrated in codons 74-84 in progressive liver disease and in codons 50-69 during clinical remission. In none of these studies was the $\mathrm{N}$-terminus of $\mathrm{HBcAg}$ considered as a hypervariable region. However, in the present study, nine mutations were found in the first $38 \mathrm{AAs}$ of $\mathrm{HBcAg}$, particularly in MCR1 (codons 21-38). These N-terminal mutations either appear shortly before the occurrence of HCC or occur specifically in HCC cases and, therefore, could not be observed in patients at the chronic hepatitis stage. Further investigation with the use of sequential serum samples of HCC patients will be required to clarify the temporal relationship between the presence of $\mathrm{HBcAg} \mathrm{N}$-terminal mutation and HCC.

The HBV core protein is a principle target for immune response. It contains numerous epitopes for human CD4+ T cell (AA 1-20, AA 50-69 and AA 127-133), CTL (AA 18-27, AA 88-96 and AA 141-151) and B cell recognition (AA 74-89, AA 107-118 and AA 127-133) [30]. In chronic hepatitis patients, mutations have been found to preferentially locate within or flanking the dominant epitopes. In this study, HBcAg mutations were found to affect both $\mathrm{T}$ and $\mathrm{B}$ epitopes. Of the three major MCRs, MCR3 and MCR5 were in B cell epitopes (AA 74-89 and AA 127-133), while one (MCR4) overlapped with a CTL epitope (AA 88-96). Among the three minor MCRs, one (MCR2) was in a T helper epitope (AA 50-69) and two (MCR1 and MCR6) overlapped with CTL epitopes (AA 18-27 and AA 141-151, respectively). Each of the seven internal deletions affected a CTL epitope (AA 88-96) and a B cell epitope (AA 74-89) in the middle of HBcAg. As most of the $\mathrm{HBcAg}$ mutations occurred after the start of elevation of serum ALT levels and hepatitis B e antigen seroconversion $[13,23,31]$, it was generally believed that the mutations were a result of selective pressure from the immune response. Whether $\mathrm{HBcAg}$ substitutions cause severe disease by inducing a naive immune response or merely immune escape has not been resolved. The missense mutations clustered in the CTL epitopes may break the immune tolerance and elicit stronger CTL-mediated immune clearance. Alternatively, mutations clustered in B-cell epitopes may result from an ineffective anti-HBc B cell response and may account for the ongoing disease and selection of mutations after seroconversion. In addition, mutations in the major $\mathrm{T}$ helper epitopes have been proposed to allow immune escape and minimize immune-mediated hepatitis, thus leading to clinical remis- 
sion [26]. However, these hypotheses are highly suggestive and will need further in vivo experiments for confirmation. The finding that $\mathrm{HBcAg}$ mutations in $\mathrm{HCC}$ affect all three types of epitopes reflects a complex interplay between the virus and the host during the course of chronic HBV infection. While some mutations may elicit a strong immune response in the immune tolerant phase, other mutations could allow for escape from the immune clearance after seroconversion. Whatever the impact on the immune response, mutation in $\mathrm{HBcAg}$, such as $\mathrm{F} / \mathrm{I} 97 \mathrm{~L}$, has been shown to enhance viral replication capacity and immature secretion [32-34]. Alteration at codon 97 was also found to be present at a high frequency in the HCC tissues in our study. The prolonged viral persistence, either by variants escaping from immune clearance or variants conferring a growth advantage, can lead to continuous hepatocyte injury and subsequent regeneration, which is one of the major mechanisms for HCC development.

Very few studies have simultaneously examined the mutations of $\mathrm{HBcAg}$ in tumor and surrounding nontumor tissues. HCC children have been reported to have more mutations in the core gene than HBV chronic carriers [14]. However, in this study we found that the missense mutations in tumor tissues were significantly lower than those in adjacent nontumor tissues $(\mathrm{p}<0.05)$, probably because the viruses in the tumor have had a reduced replication activity due to the unfavorable microenvironment. In contrast, those in the adjacent nontumor liver tissue retain a high replication rate and have had opportunity to accumulate more errors. Alternatively, in cases where replicating viruses were at a low level, the sequences isolated from HCC tissues may represent the integrated form of HBV DNAs. As HBV integration could occur at any stage of the infection $[35,36]$, it is reasonable to assume that the integrated HBV DNA contained fewer mutations compared with the replicative form of HBV in nontumor tissues. These hypotheses will need to be tested in the future by examining the HBV DNA level as well as the integration state of HBV in both tumor and adjacent nontumor liver tissues.

The limitation of this study is the lack of liver biopsies from patients at different stages of chronic hepatitis. No such sequence information in the previous literature was available to us to make the comparison. Therefore, the exact role of mutations, particularly those located in the $\mathrm{N}$-terminus of $\mathrm{HBcAg}$, in the development of HCC requires further study to clarify. Nevertheless, our data highlight the nature of the $\mathrm{HBcAg}$ mutation in tumor tissues of patients from an HCC-prevalent area. Occurrence of AA substitutions in MCRs might be used as an indicator of disease progression.

\section{Acknowledgement}

This work was supported by the Chinese State Key Project Specialized for Infectious Diseases (No. 2008ZX10002-015).

\section{References}

$\checkmark 1$ Liaw YF, Chu CM: Hepatitis B virus infection. Lancet 2009;373:582-592.

2 Lin CL, Kao JH: Hepatitis B viral factors and clinical outcomes of chronic hepatitis B. J Biomed Sci 2008;15:137-145.

3 Cao GW: Clinical relevance and public health significance of hepatitis B virus genomic variations. World J Gastroenterol 2009; 15:5761-5769.

-4 Yang HI, Yeh SH, Chen PJ, Iloeje UH, Jen CL, Su J, Wang LY, Lu SN, You SL, Chen DS, Liaw YF, Chen CJ: Associations between hepatitis $B$ virus genotype and mutants and the risk of hepatocellular carcinoma. J Natl Cancer Inst 2008;100:1134-1143.

-5 Kuang SY, Jackson PE, Wang JB, Lu PX, Munoz A, Qian GS, Kensler TW, Groopman JD: Specific mutations of hepatitis B virus in plasma predict liver cancer development. Proc Natl Acad Sci USA 2004;101:35753580.

\footnotetext{
6 Yuen MF, Tanaka Y, Shinkai N, Poon RT, But DY, Fong DY, Fung J, Wong DK, Yuen JC, Mizokami M, Lai CL: Risk for hepatocellular carcinoma with respect to hepatitis B virus genotypes $\mathrm{B} / \mathrm{C}$, specific mutations of enhancer II/core promoter/precore regions and HBV DNA levels. Gut 2008;57:98-102.

$\checkmark 7$ Chen CH, Hung CH, Lee CM, Hu TH, Wang JH, Wang JC, Lu SN, Changchien CS: Pre-S deletion and complex mutations of hepatitis $B$ virus related to advanced liver disease in $\mathrm{HBeAg-negative} \mathrm{patients.} \mathrm{Gastroenterology}$ 2007;133:1466-1474.

-8 Liu S, Zhang H, Gu C, Yin J, He Y, Xie J, Cao G: Associations between hepatitis B virus mutations and the risk of hepatocellular carcinoma: a meta-analysis. J Natl Cancer Inst

\begin{abstract}
0 Chuang WL, Omata M, Ehata T, Yokosuka O, Ito Y, Imazeki F, Lu SN, Chang WY, Ohto $\mathrm{M}$ : Precore mutations and core clustering mutations in chronic hepatitis B virus infection. Gastroenterology 1993;104:263-271. O, Ohto M: Concentrating missense mutations in core gene of hepatitis B virus. Evidence for adaptive mutation in chronic hepatitis B virus infection. Dig Dis Sci 1993;38: 594-600. cumulation of mutations in precore core region of $\mathrm{HBV}$ in patients with chronic active hepatitis: implications of clustering changes in a small region of the HBV core region. J Med Virol 1996;48:38-46.
\end{abstract}

11 Chuang WL, Omata M, Ehata T, Yokosuka

12 Hur GM, Lee YI, Suh DJ, Lee JH: Gradual ac-
} 2009;101:1066-1082.

-9 Akarca US, Lok AS: Naturally occurring hepatitis B virus core gene mutations. Hepatology 1995;22:50-60. 
13 Karasawa T, Shirasawa T, Okawa Y, Kuramoto A, Shimada N, Aizawa Y, Zeniya M, Toda G: Association between frequency of amino acid changes in core region of hepatitis B virus (HBV) and the presence of precore mutation in Japanese HBV carriers. J Gastroenterol 1997;32:611-622.

14 Ni YH, Chang MH, Hsu HY, Tsuei DJ: Different hepatitis B virus core gene mutations in children with chronic infection and hepatocellular carcinoma. Gut 2003;52:122-125.

15 Sung FY, Jung CM, Wu CF, Lin CL, Liu CJ, Liaw YF, Tsai KS, Yu MW: Hepatitis B virus core variants modify natural course of viral infection and hepatocellular carcinoma progression. Gastroenterology 2009;137:16871697.

16 Chen JG, Zhu J, Parkin DM, Zhang YH, Lu JH, Zhu YR, Chen TY: Trends in the incidence of cancer in Qidong, China, 19782002. Int J Cancer 2006;119:1447-1454.

17 Sun Z, Ming L, Zhu X, Lu J: Prevention and control of hepatitis B in China. J Med Virol 2002;67:447-450.

18 Tamura K, Dudley J, Nei M, Kumar S: MEGA4: Molecular Evolutionary Genetics Analysis (MEGA) software version 4.0. Mol Biol Evol 2007;24:1596-1599.

19 Nassal M: The arginine-rich domain of the hepatitis B virus core protein is required for pregenome encapsidation and productive viral positive-strand DNA synthesis but not for virus assembly. J Virol 1992;66:41074116.

20 Petit MA, Pillot J: $\mathrm{HBc}$ and $\mathrm{HBe}$ antigenicity and DNA-binding activity of major core protein p22 in hepatitis B virus core particles isolated from the cytoplasm of human liver cells. J Virol 1985;53:543-551.
21 Ehata T, Omata M, Chuang WL, Yokosuka O, Ito Y, Hosoda K, Ohto M: Mutations in core nucleotide sequence of hepatitis $B$ virus correlate with fulminant and severe hepatitis. J Clin Invest 1993;91:1206-1213.

- 22 Ehata T, Omata M, Yokosuka O, Hosoda K, Ohto M: Variations in codons $84-101$ in the core nucleotide sequence correlate with hepatocellular injury in chronic hepatitis B virus infection. J Clin Invest 1992;89:332338.

23 Bozkaya H, Ayola B, Lok AS: High rate of mutations in the hepatitis $\mathrm{B}$ core gene during the immune clearance phase of chronic hepatitis B virus infection. Hepatology 1996;24: 32-37.

24 Khakoo SI, Ling R, Scott I, Dodi AI, Harrison TJ, Dusheiko GM, Madrigal JA: Cytotoxic T lymphocyte responses and CTL epitope escape mutation in $\mathrm{HBsAg}$, anti-HBe positive individuals. Gut 2000;47:137-143.

25 Pumpens P, Grens E: HBV core particles as a carrier for B cell/T cell epitopes. Intervirology 2001;44:98-114.

26 Carman WF, Boner W, Fattovich G, Colman K, Dornan ES, Thursz M, Hadziyannis S: Hepatitis B virus core protein mutations are concentrated in $\mathrm{B}$ cell epitopes in progressive disease and in T helper cell epitopes during clinical remission. J Infect Dis 1997;175: 1093-1100.

27 Ehata T, Omata M, Yokosuka O, Hosoda K, Ohto M: Amino acid residues of core region of hepatitis B virus. Asymptomatic carriers versus patients with liver disease. J Gastroenterol Hepatol 1991;6:292-296.

28 Hosono S, Tai PC, Wang W, Ambrose M, Hwang DG, Yuan TT, Peng BH, Yang CS, Lee CS, Shih C: Core antigen mutations of human hepatitis B virus in hepatomas accumulate in MHC class II-restricted T cell epitopes. Virology 1995;212:151-162.
29 Kim HJ, Lee DH, Gwak GY, Choi MS, Lee JH, Koh KC, Paik SW, Yoo BC: Analysis of the core gene of hepatitis B virus in Korean patients. Liver Int 2007;27:633-638.

-30 Vanlandschoot P, Cao T, Leroux-Roels G: The nucleocapsid of the hepatitis B virus: a remarkable immunogenic structure. Antiviral Res 2003;60:67-74

31 Lim SG, Cheng Y, Guindon S, Seet BL, Lee LY, Hu P, Wasser S, Peter FJ, Tan T, Goode M, Rodrigo AG: Viral quasi-species evolution during hepatitis $\mathrm{B}$ e antigen seroconversion. Gastroenterology 2007;133:951-958.

32 Suk FM, Lin MH, Newman M, Pan S, Chen SH, Liu JD, Shih C: Replication advantage and host factor-independent phenotypes attributable to a common naturally occurring capsid mutation (197L) in human hepatitis B virus. J Virol 2002;76:12069-12077.

33 Yuan TT, Sahu GK, Whitehead WE, Greenberg R, Shih C: The mechanism of an immature secretion phenotype of a highly frequent naturally occurring missense mutation at codon 97 of human hepatitis B virus core antigen. J Virol 1999;73:5731-5740.

34 Yuan TT, Tai PC, Shih C: Subtype-independent immature secretion and subtype-dependent replication deficiency of a highly frequent, naturally occurring mutation of human hepatitis B virus core antigen. J Virol 1999; 73:10122-10128.

35 Brechot C, Pourcel C, Louise A, Rain B, Tiollais P: Presence of integrated hepatitis B virus DNA sequences in cellular DNA of human hepatocellular carcinoma. Nature 1980; 286:533-535.

36 Murakami Y, Saigo K, Takashima H, Minami M, Okanoue T, Brechot C, Paterlini-Brechot P: Large scaled analysis of hepatitis $B$ virus (HBV) DNA integration in HBV related hepatocellular carcinomas. Gut 2005;54: 1162-1168. 